\title{
Pengunaan Teknik Keamanan Pada Jaringan Serat Optik dengan Metode Anti-Jamming dan Steganografi Menggunakan Modul Optisystem
}

\author{
Mia Rosmiati ${ }^{*}{ }^{1}$, Arindra Rizky ${ }^{2}$, Ian Pramana Depari ${ }^{3}$ \\ 1,2,3 Universitas Telkom Bandung \\ mia@tass.telkomuniversity.ac.id ${ }^{*}$, ndrpurba@gmail.com², ianpramanadepari@gmail.com³
}

\begin{abstract}
Abstrak
Serat optic merupakan media transmisi yang dapat menghantarkan informasi dalam bentuk cahaya. digunakannya cahaya sebagai media penghantar informasi membuat media ini dapat menghantarkan informasi dengan kapasitas besar dalam waktu yang sangat singkat. Sehingga saat ini serat optic banyak digunakan dalam Telekomunikasi. jaringan serat optic ini harus disertai dengan teknik keamanan yang andal dalam proses transmisi informasinya, karena jika terjadi penyerangan dalam jaringan yang serat optic maka data yang akan diterima oleh receiver akan jauh berbeda dengan data yang dikirim transmitter. Sehingga hal ini sangat fatal jika informasi yang dikirimkan memiliki tingkat kerahasiaan yang sangat tinggi seperti informasi keamanan Negara. Adapun metode yang dapat digunakan dalam pengamanan jaringan serat optic adalah metode Steganography dan metode Anti-jamming. Dari percobaan yang telah dilakukan terlihat bahwa teknik Steganography memiliki tingkat keandalan yang lebih baik jika dibandingkan dengan metode anti-jamming dengan nilai BER untuk metode steganography adalah $1.91219 \mathrm{e}-077$.
\end{abstract}

Kata kunci: Jaringan Serat Optic, Steganography, Anti-jamming, BER

\begin{abstract}
Fiber optics is a transmission medium used to convert information into optical (light). As an transmission medium, light can deliver enormous information-carrying capacity in a very short time. Thus, make fiber optics commonly used in telecommunication. This fiber optics should be equipped with reliable protection during the transmission process because once it got attacked, the data received would be much different from the actual data sent by the transmitter. Therefore, it could be quite dangerous when the data being sent requires high level confidentiality, such as National information security. Anti-jamming and Steganography method can be used to protect the fiber optics. The experiment conducted shows that Steganography mehod has higher reliablity compared to anti-jamming method with the BER values for steganography method is $1.91219 \mathrm{e}-077$.
\end{abstract}

Keywords: Fiber-Optic Network, Steganography, Anti-jamming, BER

\section{Pendahuluan}

Serat optic adalah suatu kabel terbuat dari $\mathrm{SiCl}_{4}$, berfungsi untuk menghantarkan cahaya yang mengandung informasi dengan kecepatan yang sangat tinggi ke receiver. Adapun untuk transmisi cahaya dalam fiber optic [1] bisa dilihat Gambar 1, terdapat tipe perambatan cahaya dalam fiber optic, yaitu:

1. Perambatan cahaya yang bergerak lurus di dalam fiber optic, sehingga cahaya mengalami transmisi jarak jauh.

2. Perambatan cahaya yang mengalami pemantulan (refleksi) di dalam fiber optic, hal ini dikarenakan diameter core lebih besar dibandingkan panjang gelombang cahaya, sehingga ada dua atau lebih cahaya yang dapat merambat pada media yang sama.

3. Cahaya mengalami pembiasan (refraksi), hal ini dikarenakan sudut cahaya datang lebih kecil dibandingkan sudut kritisnya, mengakibatkan cahaya tidak dapat merambat dalam fiber optic. 


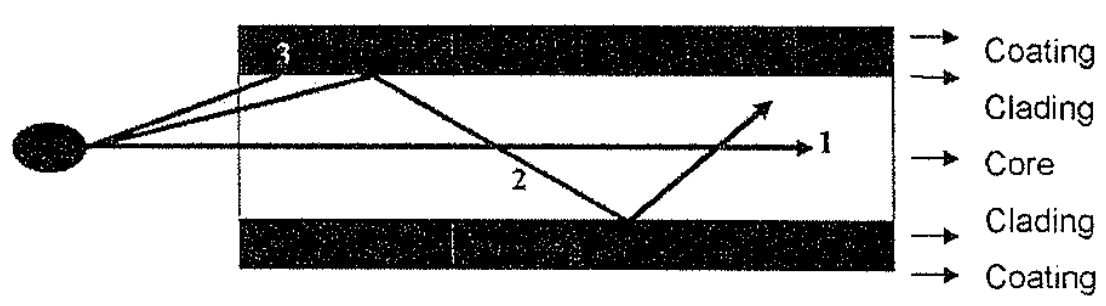

Gambar 1. Perambatan Cahaya di dalam Fiber Optik

Jika dilihat dari 3 fenomena diatas, maka ada dua hal yang harus dipenuhi agar cahaya dapat merambat dalam fiber optic, yaitu sudut datang harus lebih besar dari sudut kritis serta indeks bias core harus lebih besar dari indeks bias cladding.

Pada saat ini, jaringan kabel fiber optic sangat banyak digunakan untuk menunjang komunikasi dalam mengirim dan menerima data. Dengan menggunakan kabel fiber optic pengiriman data dapat lebih cepat tanpa perlu menunggu lama agar data sampai ke penerima. Pada saat mengirim data harus diperhatikan juga keamanan data yang dikirim agar data sampai ke tujuan yang diinginkan tanpa adanya gangguan dari pihak ketiga.

Meskipun kemungkinan data yang dikirim aman tetapi terkadang ada pihak ketiga yang ingin mengetahu data yang dikirim tersebut sehingga data yang dikirim tidak aman. Dalam hal ini sudah terjadi ancaman untuk pengirim, karena data yang dikirim tersebut dapat diketahui oleh pihak ketiga sehingga data tersebut tidak aman. Proses penyerangan dalam jaringan serat optic banyak dilakukan dengan cara melakukan bending (pembelokan pada serat optic utama), sehingga terdapat sebagian sinyal yang keluar dari core. Sinyal yang keluar dari core ini dapat di tapping oleh serat optic penyadap sehingga pihak ketiga dapat mengetahui informasi yang ditransmisikan oleh transmitter ke receiver. Oleh sebab itu, metode Steganography dan Antijamming dapat digunakan untuk meningkatkan keamanan dalam jaringan serat optic.

Metode Optical Steganography [2] bertujuan untuk meningkatkan privasi komunikasi dengan menyembunyikan sinyal dalam publik channel, sehingga tidak ada yang mengetahui keberadaan sinyal tersebut. Prinsip dasar dari Optical Steganoggrafi adalah merenggangkan pulsa data stealth secara temporal menggunakan dispersi tinggi dan Amplitudo dari pulsa yang cepat menurun setelah terjadi perenggangan sinyal sehingga sinyal dapat disembunyikan di publik channel.

Anti-jamming merupakan teknik keamanan yang bertindak untuk mencegah tabrakan data dalam system mekanik dan perangkat komunikasi. Jaringan sering mendapat gangguan pada channel sinyal dengan strong, noise, dan Anti-jamming memiliki peran keamanan yang kuat serta mempunyai kecepatan pada proses. Adanya Anti-jamming, data tidak ada yang akan bertabrakan dan akan secara utuh didapat oleh penerima, lalu penyadap tidak dapat recovery data. Sehingga data yang didapat lebih cepat dan utuh [3].

Teknik keamanan yang digunakan ini berfungsi untuk mengamankan lapisan fisik serat optic, hal ini dikarenakan lapisan fisik serat optic sangat berperan penting dalam pengiriman informasi dengan menggunakan media serat optic, karena informasi yang dilewatkan berupa cahaya bertransmisi menggunakan prinsip gelombang cahaya dan berdasarkan indeks bias media. Sehingga jika media transmisi mengalami kerusakan, maka informasi dapat mengalami kerusakan dalam jumlah yang cukup besar.

\section{Metode Penelitian}

Metode penelitian yang digunakan melalui simulasi optisystem untuk penggunaan dua teknik keamanan yang berbeda pada jaringan serat optic adalah metode Waterfall, seperti terlihat pada Gambar 2.

Proses inisiasi merupakan sebuah tahapan untuk menentukan teknik keamanan yang dibutuhkan jaringan serat optik, proses desain, dan implementasi pengujian dilakukan melalui aplikasi optical system. Proses desain keamanan yang digunakan adalah teknik Steganography dan Anti-jamming, sedangkan proses pengujian dilakukan dengan cara melihat nilai bit error rate (BER) terhadap data yang diterima oleh receiver setelah dilakukan proses penyerangan selama bertransmisi menggunakan media fiber optik, dengan cara membandingkan nilai BER untuk setiap teknik keamanan yang digunakan. Maka dapat ditentukan metode yang terbaik dalam mengirimkan data dengan menggunakan media fiber optik. Adapun desain jaringan serat optik dengan menggunakan teknik keamanan Steganography ditunjukkan oleh Gambar 3. 


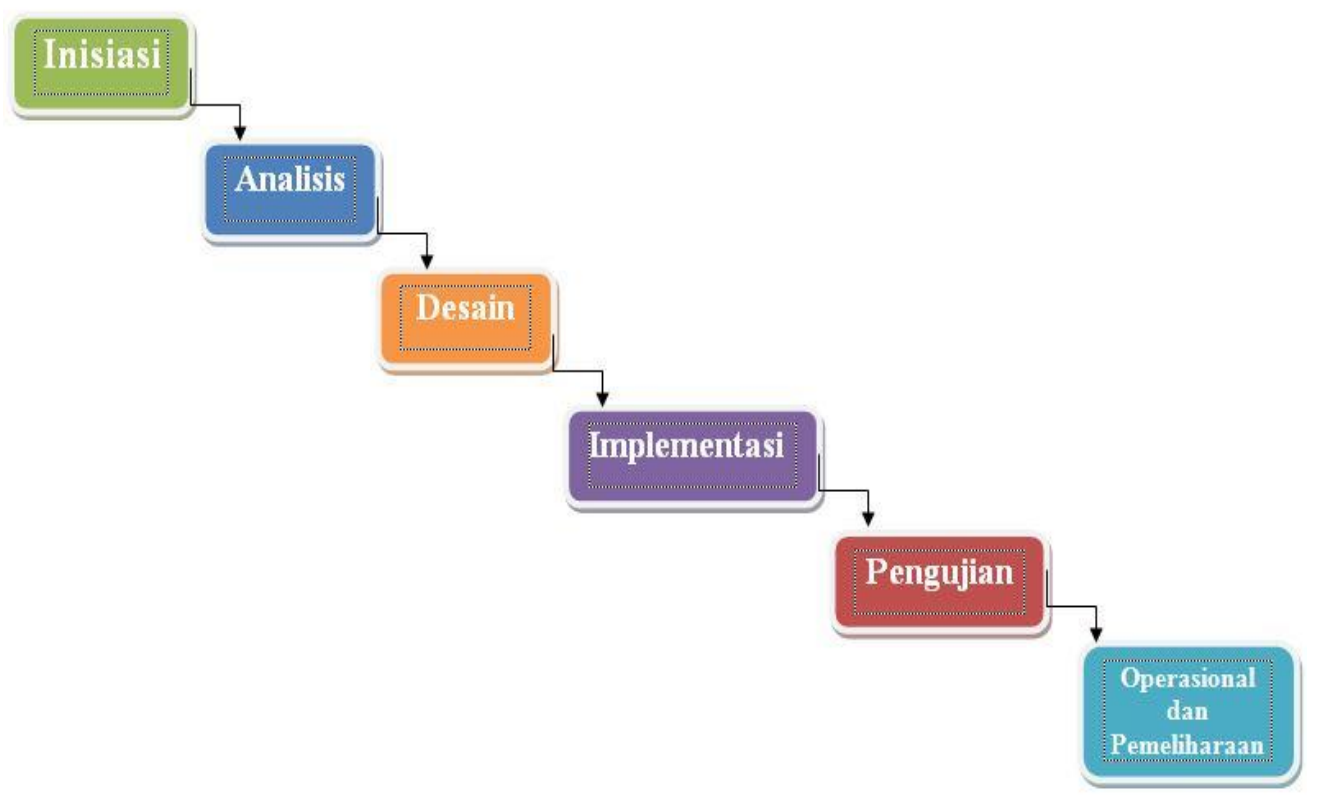

Gambar 2. Metode Waterfall

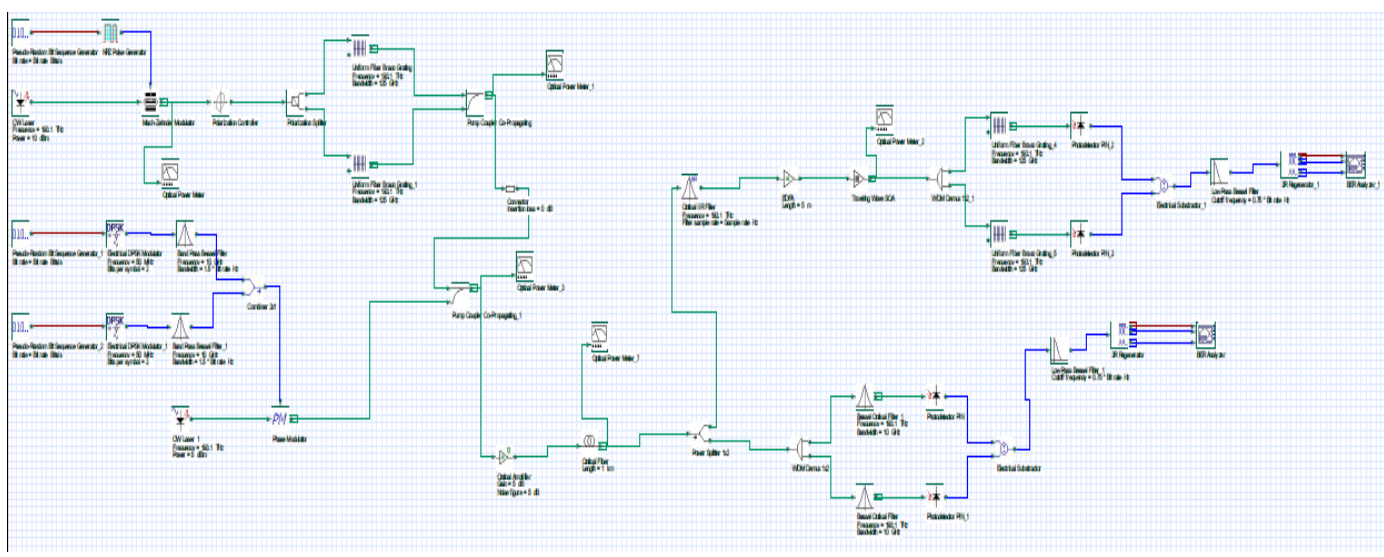

Gambar 3. Desain Jaringan Serat Optik dengan Menggunakan Optical Steganography.

Pada Gambar 3 terlihat bahwa jaringan serat optic terbagi menjadi dua, yaitu stealth channel dan public channel, dimana public channel berfungsi sebagai jaringan yang diserang dan tanpa menggunakan teknik keamanan. Dalam jaringan stealth channel berfungsi untuk mengamankan data dengan menyelipkan jaringan public channel menggunakan connector dalam menghubungkan stealth channel dan public channel, kemudian data diteruskan melalui EDFA (erbium-doped fiber amplifier), serta optical fiber, lalu dipecah menggunakan splitter, pada bagian receiver data tanpa menggunakan keamanan dan bagian splitter kedua jaringan di filter ke EDFA (erbium-doped fiber amplifier), maka sinyal di compressor akan meningkatkan sinyal, kemudian masuk ke spliter dan data di decoder.

Gambar 4, jaringan serat optic menggunakan metode Anti-jamming, fungsi pump laser bertujuan untuk meningkatkan daya yang dikirimkan oleh transmitter, sehingga dengan adanya variasi daya yang digunakan pada pump laser maka data yang dilewatkan pada media serat optic dapat diamankan dari pihak ketiga. 


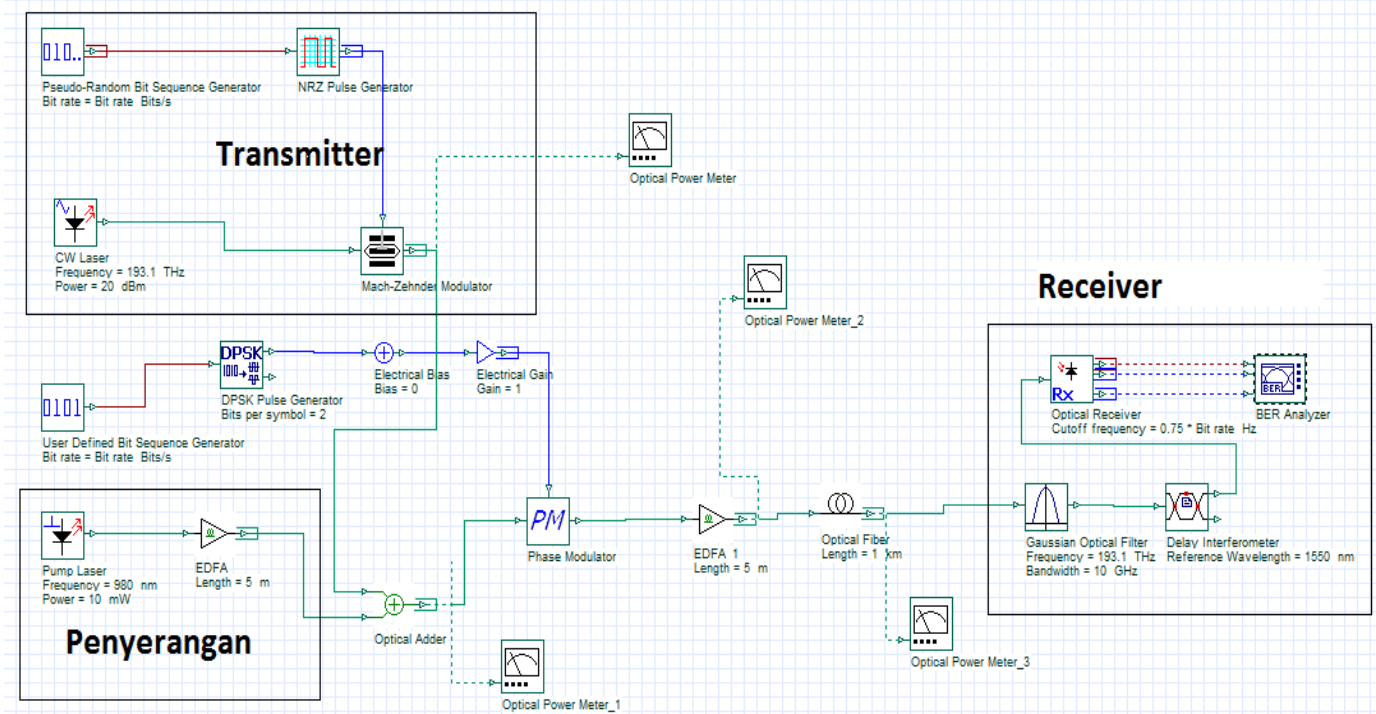

Gambar 4. Jaringan Serat Optic dengan Menggunakan Metode Anti-jamming

\section{Hasil Penelitian dan Pembahasan}

Proses pengujian keandalan system diukur berdasarkan nilai BER untuk jaringan serat optic menggunakan metode Steganography dan pengukuran BER dengan metode Antijamming. Percobaan teknik keamanan menerapkan metode Optical Steganography dengan power $10 \mathrm{dBm}$ untuk transmitter serta $5 \mathrm{dBm}$ pada $\mathrm{Cw}$ laser dan panjang kabel optik $1 \mathrm{Km}$.

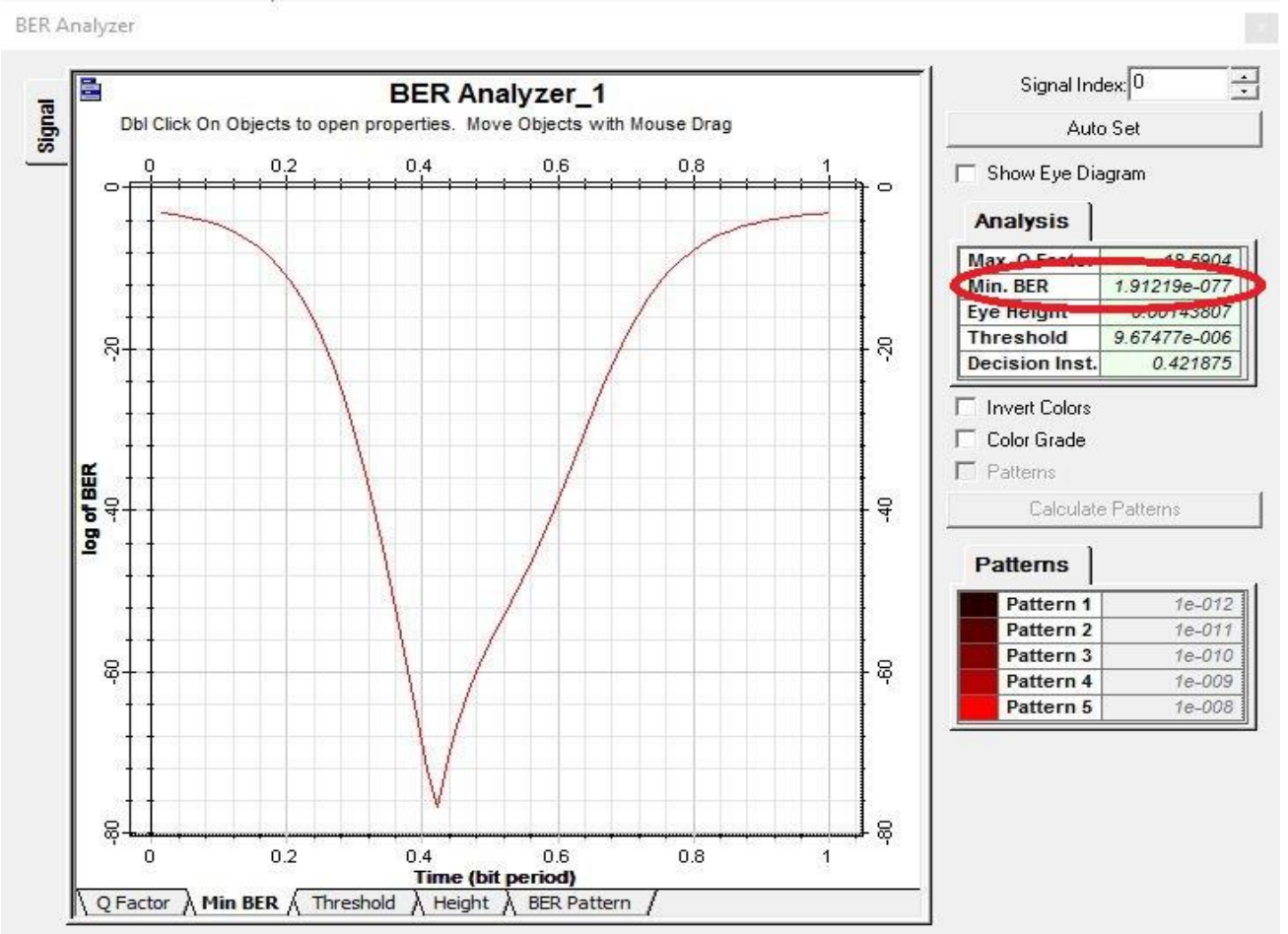

Gambar 5. Nilai Bit Error Rate untuk Public Channel

Pada Gambar 5 menunjukkan nilai BER untuk jaringan fiber optic dengan Optical Steganografi di stealth channel adalah $1.91219 \mathrm{e}-077$. Sedangkan besarnya nilai BER untuk jaringan serat optic menggunakan metode Anti-jamming. Berdasarkan Gambar 6 terlihat besarnya nilai BER untuk jaringan serat optik dengan teknik keamanan Anti-jamming adalah 4.33e-018. 


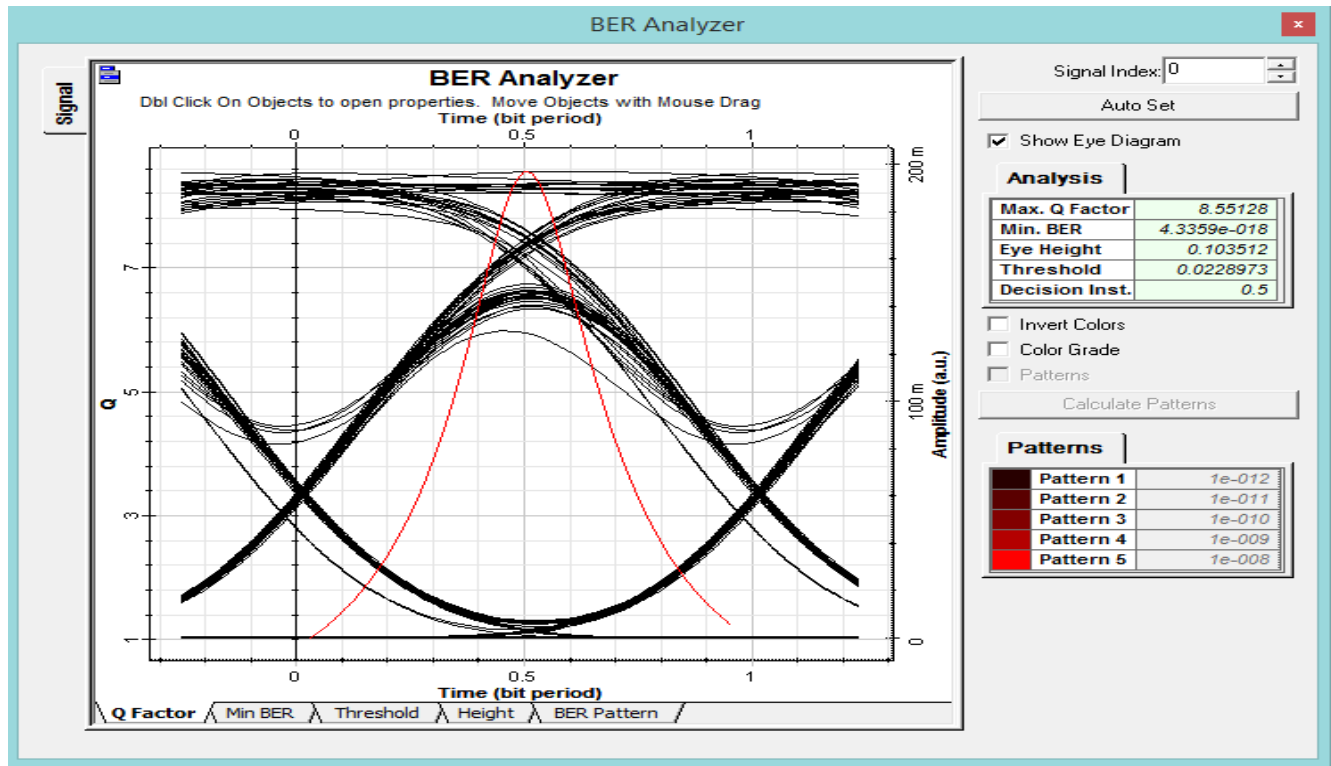

Gambar 6. Pengukuran Bit Error Rate untuk Teknik Keamanan dengan Menggunakan Metode Anti-jamming

\section{Kesimpulan}

Berdasarkan pengujian yang dilakukan melalui penyerangan pada jaringan serat optik dengan menggunakan metode keamanan Steganography menunjukkan nilai BER yang lebih kecil dibandingkan dengan metode Anti-jamming, hal ini menunjukkan metode Steganography memiliki tingkat keandalan yang lebih baik jika dibandingkan dengan metode Anti-jamming dalam menghadapi penyerangan pada jaringan serat optic. Adapun penelitian yang dapat dilakukan untuk tahap berikutnya, yaitu dengan melakukan perbandingan pengukuran daya yang diterima oleh receiver setelah dilakukan penyerangan pada jaringan serat optic.

\section{Referensi}

[1] G. P. Agrawal. "Fiber-Optic Communication Systems." Vol. 3. 2002.

[2] B. J. Ben Wu. "Optical Steganography, Secure Communicaation in Fiber-Optic Networks." 2014.

[3] John Doe. "Internet Usage Within Nations." Boston: Boston Publishing. 2000.

[4] Optisystem, "Optisystem," Optical Communication System Amplifier Design Software, 2009.

[5] Z.Wang. "Improving the Privacy of Optical Steganography with Temporal Phase Masks." Opt. Express. Vol. 18. 2010.

[6] OptiSystem. OptiSystem Tutorials-Volume 1 and volume 2. 2014.

[7] Pramana, Ian Depari, "Pembangunan Teknik Keamanan Pada Jaringan Serat Optik dengan Metode Optical Steganography Melalui Modul Optisystem”, Buku Proyek Akhir Universitas Tekom, 2016.

[8] Rizki, Arindra S. Purba, "Pembangunan Teknik Keamanan pada Jaringan Serat Optik dengan Metode Anti-Jamming Melalui Modul Optisystem" Buku Proyek Akhir Universitas Tekom, 2016. 
